\title{
3. Beyond New Public Management: Will governments let citizens and communities determine policy choices and service mixes?
}

\author{
Don Kettl
}

On a previous trip to Australia, some 15 years ago, I had a conversation with academics and practitioners about the idea of putting citizens at the centre of policy-making processes. This topic frames my contribution to this volume of essays. Are governments really ready to let go of their hold on the policymaking process? The simple answer is 'no'. The bigger problem is whether citizens are ready to step up - and the answer to that question is 'maybe'.

There is a transformation currently underway which will bring citizens into the decision-making process and adjust to the realities of governance in the 21 st century. The success of this transformation, however, requires us to address two important issues.

The first is whether we are essentially at the end of a phase of citizen engagement in government, and whether new ideas are surfacing. The second is how this issue is playing out in nations around the world.

We have spent two generations betting on expanding the role of citizens in government. One of the enormous breakthroughs and contributions to the philosophy of new public management (NPM) was the idea that government is too disconnected from citizens and not responsive enough to their needs. By finding a way to make government more efficient and more responsive, the movement suggested, we could forge a fundamental change in the way in which government operates. We have now spent a significant amount of time attempting to advance this movement. This has been accelerated by the 24-hour news cycle, which has made it impossible for anybody to go anywhere without being connected constantly to what is happening elsewhere.

Compared with the 1980s, when NPM was first being adopted, the connection between citizens and government is now easier to follow. When I visited Australia recently I was able to follow on television not only the Australian perspective on US financial problems, but also the live debates occurring halfway around the world in Washington DC. And when I return to the United States, I can similarly watch political events occurring in Australia and New Zealand. 
There are three vignettes that help make this point. Consider Michelle Bachmann, who was for a time a leading candidate for the Republican nomination in the 2012 US presidential election. She is a leader of the Tea Party movement and has said that it is time 'for tough love for the American government'. She emphasised 'I will not raise taxes, I will reduce spending and I will not vote to raise the debt ceiling'. The Tea Party movement has roots in the United States, going back to the 1770s when American revolutionaries dressed up as American Indians to invade British ships. By throwing tea into the harbour in Boston, they helped spark not just opposition to taxes but rebellion against British rule.

Unlike Australia and New Zealand, Americans decided 200 years ago to go to war to end the rule of the British crown. The constitutional system that was devised as a result made it hard for anyone to do anything quickly — and sometimes to do anything at all. Australians and New Zealanders have been more patient and have maintained more confidence in government.

The Tea Party movement has tapped into a reservoir of concern in the United States about the essence of government. In the United States, there are powerful arguments that we have too much government; that it is time to downsize and shrink government. Government considers citizen engagement to be a key step towards this end, but other measures are necessary. In the United States and around the world, we are nearing a major tipping point. A recent article in the Economist opined that 'Australians must now decide what sort of country they want their children to live in' ('Australia's Promise: The next golden state', 26 May 2011). The debate is not only about the size of government, but what it is that government ought to be. In a recent question time in the New Zealand parliament, a parliamentarian referred to the forum as increasingly ineffectual and cynical: 'I worry that it [question time] is turning into a contest to see who can make the most noise. Question time is not about that'. The United States does not have question time - a blessing, considering that existing US policy debates are similarly tense and cynical.

Against this bleak backdrop, the connection between citizens and government is important. Citizen engagement is now, however, about much more than co-production. It has evolved far beyond the aim of improving efficiency. Increasingly, the focus is on the identity and values of governments: who we are, what we want to be, and how we are going to achieve our objectives. This is just as fundamental as it was at the beginning of the NPM movement.

Over the last decades, there have been improvements in the efficiency of government around the world because of the reforms introduced by NPM. But, despite these efforts, there has been a decline in support for public institutions. And, in the aftermath of recent economic collapse, tight fiscal constraints will remain for some time. The idea of going back to normal, as many people hoped 
in late 2008, seems to be a pipedream. In the United States there is a phrase about the 'new normal', with fiscal constraints now the inescapable imperative of our age. That, in turn, is driving the sense of what it is we want government to do.

Democrats are now talking about cuts, and they are battling Republicans to see who can downsize government the most. We are talking about a radical reshaping of what it is the government does in a way that also simultaneously holds out demands for better performance. People might not like or trust government much, but every problem that emerges quickly becomes a public problem.

Recently I participated in a panel discussion about the $2010 \mathrm{BP}$ oil spill in the Gulf of Mexico. This was an unusual public problem in that the oil rig was owned by BP, a private company, and it blew up beyond American waters. Despite this being a failure of a private company in international waters, the public immediately looked to the government to step in and solve the problem. We might hear from citizens that they want less government and fewer taxes, but, when a problem arises, we expect instant response from government.

Consider the levels of trust in government in the United States (or lack thereof). The technical explanation is not a happy story. In 1960, trust in government was relatively high. It fell during the Vietnam War and hit a low point in 1980. During the presidency of Ronald Reagan, trust began to grow but it collapsed again in the 1990s. In the aftermath of the terrorist attacks on the United States in 2001, and the continuing policy gridlock that prevails in Washington, public trust and confidence in government has declined again. Polling suggests that people really do not much like or trust President Barak Obama, but they dislike and trust the Republicans even more.

Other nations speak of hung parliaments; in the United States, there are a lot of people who would like to hang the parliament. At this point, there is a sense that nobody is in charge. The system of government requires everybody to work together, but nobody wants to work on anything. I do not believe that this is because our representatives are nasty people; rather, they are good people whose wide range of views militates against them achieving compromise in an increasingly constrained political system. The tense and cynical atmosphere in Washington is, therefore, less about particular policy debates and more a crisis about what government is and what citizens' relationship to that government will be. Distrust in government is not just an American problem, but it is certainly higher in that country than in most Western democracies.

So, during the NPM era, fundamental issues have been confronted, but continue to require resolution. A series of management reforms have been implemented in an effort to try to sort these issues out. Public sectors have been transformed 
according to a theory that the things government should do can be assigned to agencies to produce those results. We put leaders in charge and held them accountable for their outputs and ultimately for the outcomes. We have been spending roughly the last 20 years trying to put boundaries around problems and trying to make those boundaries work more effectively. Now we struggle to connect those boxes more with citizens.

In the Westminster approach to these government reforms, there has been a focus on making departmental managers more accountable. At the same time, however, there has been an increasing realisation that agencies need to work with each other across agency boundaries. Consequently, we now grapple with a puzzle of how to prevent the boundaries around the agencies from frustrating the ability of managers to manage effectively and prevent them complicating the problem of coordinating action. That puzzle has begun to collide with the logic of the reforms that have been underway for the last 15 or 20 years.

Then there is the American approach, which is based on letting the managers manage; liberating managers to be able to do what it is that they intuitively know should be done. This philosophy has collided with incredible political pressures (where politicians seek to meddle) and in turn has created strong incentives for managers simply to keep their heads down to avoid having them shot off in the tough political battle.

In short, we have reached an end of reform, in two respects. First, we have reached the end of the logical progression of what we have been working on for the last 15 or 20 years in the public sector. We have done moderately well, but we have now reached the point where the reforms that we launched have gone as far as they can. Second, we are now struggling to redefine the purpose of our reform endeavours. What is government's role in reform in the 21 st century and how are we going to make that work?

This is a very tough set of questions that goes far beyond the framework that has driven reforms for the last 15 years.

We have produced some dramatic gains, but we have also placed more boundaries between agencies along the way. Can you think of any problem that matters that any one organisation can control? I have not found anyone who can come up with even one example. And if that is the case, we will increasingly depend on the ability of agencies to connect with each other. That flies in the face of the reforms that have compartmentalised problems and required agencies to respond to them within their boundaries.

A related approach depends on information. I was recently at a meeting in Washington with a senior bureaucrat in the Obama administration, who admitted that the administration was collecting and distributing vast amounts 
of information - but he wasn't sure that anybody read or used the information they produced. In the information age, we know that information matters. But we do not know how to produce information that matters or with which citizens can effectively engage.

In addition is the importance of our notion of the 'big idea'. When I visited Australia in 1995, I was not only struck that there was a driving idea called the 'NPM', but also that there was a literature on it, intellectual excitement about it, and a sense that something really big was afoot. Look around now and ask yourself: what is the current 'big idea'? There is a consensus, I think, that NPM has done a lot of very important work but that it has run its course. People are looking for the next big idea, but there is currently no idea that will galvanise action as the NPM did when it was launched in New Zealand in the late 1980s.

Another problem is that the public has higher expectations for immediate results, but it is also less prepared to make the sacrifices needed to achieve them. Within government there is a sense that governments are too wasteful, and need to be downsized, but there is also greater resistance by civil servants to proposed cuts to their programs.

Citizens do not understand the necessities of reform, and politicians are too scared to tell citizens that their expectations are unreasonable. This is at the core of the question about what it is that people really expect from government. It is a major unresolved question in the United States and, I think, it is increasingly becoming so in many countries around the world. It is now accentuated by fiscal stress, which shows no signs of going away. We cannot rely on economic growth to solve this dilemma. And it is hard for the public to trust government to solve the problem because they do not tend to trust the government with big questions.

We are at a historically important moment in which we are facing some tough constraints, without a big idea to drive us, but with the inescapable necessity to solve our problems. I believe in improving customer satisfaction, in trying to create better one-stop shops, in integrating government services, and in making government more transparent. Those things are important, but we are at the point where we are making only marginal improvements that will not suffice to solve our problems and citizens' demands.

Considering this bleak portrayal, it is hard to be optimistic about our governments' ability to reform to meet its citizens' immediate expectations and address critical long-term problems. Hence, it is worth asking whether we are satisfied with what we have now - and whether what we have is as good as it is going to get. What does it mean to engage citizens in government and can we 
give them what they want? Are they willing to pay for what they want? And if we are going to continue doing what we are doing, are we going to be able to do it any better than we are now?

One of the problems is that, in the United States and indeed globally, the current political atmosphere focuses on government mistakes; there are rarely compliments for good government performance. There is no kind of expectation that the public will reward high performance, because that is why citizens pay government. The result is that government becomes risk-averse; its policy outlook more short-term. Administrators replicate this cautious behaviour by performing business as usual.

That takes us to the final puzzle about how we can bring citizens in. Consider the example of governments since the middle ages operating programs to eliminate rat infestations. During the 1910s, Philadelphia had a special 'rat receiving station', with a rat patrol wagon that would cruise the city. A more modern version of this, the 'Rat Rub-out Program', was created by the mayor of Baltimore in the early years of the 21 st century.

The program encouraged citizens to telephone a call centre to report any kind of problem, whether it be a hole in the road, sidewalk cracks - or rat infestations. When citizens called in with reports of rat infestations, the city captured the locations and mapped the areas with rat clusters. Figure 1 maps the calls received about rat problems: areas with a high concentration of rats are marked by green; these spots become darker and darker where there are more reports of bigger rats.

The next question was: if rats are a public health problem, and citizens expect government to get rid of them, how can governments achieve this? Create a department of rats? The notion of creating a new agency is, of course, absurd. The responsibility for rat infestations rests with various agencies - the Department of Health, sanitation and rubbish pick-up services, and housing agencies (because rats tend to live in abandoned buildings and, if you have too many abandoned houses, rubbish will accumulate). Delegating responsibility for exterminating rats, then, becomes a difficult task.

The solution lay in ensuring that all of the agencies with a share of the rat problem worked together. Of course, the standard approach to collaboration is this: the mayor orders everyone to collaborate; everyone says yes, then goes back to the office and nothing changes. But in Baltimore, the mayor took personal leadership, constantly monitoring the data and charts on rat infestations. It became difficult for managers to walk away from the problem because there were clear accountability measures. 


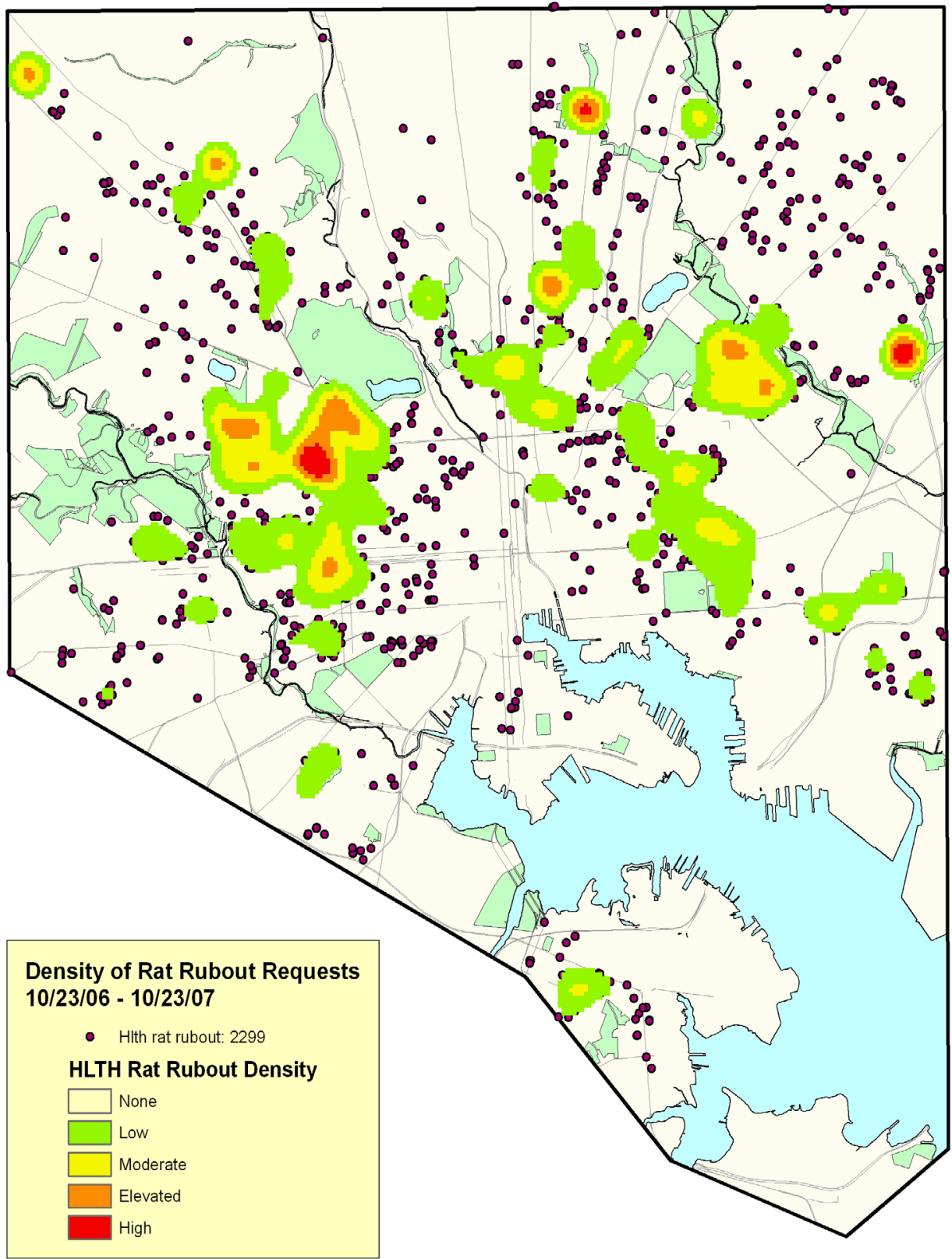

Figure 1: Rat Rub-out

Source: www.baltimorecity.gov/news/citistat/reports.html

Another example of cross-agency program delivery occurred in the aftermath of the economic crisis, when the US federal government created an \$US800 billion 
public stimulus program. The US administration's worry was that there would be manifold opportunities for fraud and waste, so it decided to track the money. But the administration went further: not only would they track the money, they made it possible for everyone else to do so by allowing anybody, anywhere, to follow what projects were going on in their street through an online mapping program. In fact, I can check on these data with my iPhone, through an app that the government designed. As a result, an $\$ 800$ billion program can be tracked to each citizen's address.

When users examine the community programs through the online mapping system, they see that one is run by a job training agency, one by a housing agency or one by a community services agency. I showed one of these charts to a first-year college student. Within 30 seconds, she asked the most important question: I wonder if they talk to each other? Once you chart the location of such numerous projects, the question of coordination becomes inescapable, because you are not only talking about programs or agencies but about neighbourhoods. You are talking about how government interacts to affect people where they live. You have accountability that operates by place and not by agency or program. It becomes impossible to walk away from the question of whether there's another program two blocks away that is very similar, run by a different agency that requires coordination. If we are interested in place-based performance, coordination becomes inescapable.

The primary concern remains whether or not anybody cares about accessing this information. Either way, giving citizens access to real-time, place-based data - not data on what happened last year or the year before or five years ago - is an accountability measure that will improve our chances of successfully engaging citizens.

The second issue is a need to redefine outcome indicators. The elimination of rat infestations should not be seen as an outcome in itself; rather, the outcome depends on a range of related factors. For example, substandard housing and dilapidated conditions in inner cities are hotspots for rat populations, therefore rats cannot be eliminated without improving housing conditions and, indeed, the overall quality of the neighbourhood. Relentless follow-up by leaders will be crucial in reinforcing this approach.

The third issue is a need to redefine accountability. Instead of traditional compliance accountability we need a new approach that focuses on the quality of services for citizens. The issue then becomes not so much making an agency or program work better, but making the neighbourhood in which citizens live work better. Having accountability and management focused on place is a 
revolutionary concept. Readers who understand NPM know that this explodes many of the underlying arguments. Its goal is to change the conversation so that it can crack the dilemmas of accountability.

Leadership is a crucial part of this new paradigm, and some points on this subject must be made. Firstly, and paradoxically, in the increasing complexity of the state, the role of individual leaders becomes more important. As part of NPM we have spent time trying to formulate constructs that encourage leaders to lead, but not investing much in our understanding of the importance of the leader per se. And it turns out that, in so doing, we have reached the limits of this insular approach, because the new types of leaders needed are the ones that are accomplished in reaching out.

The United States learned this lesson from its experience during Hurricane Katrina. The response to the hurricane was chaotic and the initial phase failed largely because of efforts to manage the program within agency boundaries. Solutions began to be found when leaders arrived and started to understand what the problem was, not while they remained off-site, managing the federal agency in charge of emergency response. There were people who were stuck on rooftops and needed to be rescued, and an effective response required crossagency collaboration and a lot of spontaneous thinking from leaders.

In many ways this is the crucial aspect of the engagement issue. Most American citizens don't know which agency will be in charge of a problem that affects them, they don't particularly care; they just want the government to respond and one of the government's problems is trying to figure out how to connect 'the problem' and 'the need for response' to the people who are going to be responsible for fixing it. The fixers, however, often lie in multiple agencies and so government's second layer problem is trying to figure out how to weave that together. Ultimately, even if citizens do not know and do not care about knowing which government agencies are responsible for addressing their problems, the government must continue with the major reforms addressed in this chapter, even in the current austere financial environment.

But there are a couple of final things to note. Service coordination may be one way of providing some reassurance to citizens that government is listening and connecting, and there are some things that are high priority and high visibility. In America, when regions are affected by snow storms, big potholes in the middle of the road or other things that annoy people, it is reassuring to know that the officials responsible for fixing these problems are taking their roles seriously and providing guarantees to fix the problems. The kind of service coordination that is required is instructive. It potentially provides a way for public officials to talk more honestly with the citizens about what it is that has to happen. 
The ongoing and proposed reforms described in this chapter are by no means certain to be the 'next big things'. But two things seem clear. First, doing more of the same is going to produce more of the same results. The declining trust in government and rising fiscal constraints would guarantee that. Second, framing today's challenges as a problem of performance and accountability, with information as the driver changing incentives, is an interesting approach that offers some hope.

The first part of this chapter might have been depressing — we do face significant challenges in government. But the second half offers significant hope. We are in the middle of a radical and exciting transformation that gives us the chance to rethink what government is, how it works and, most importantly, how it connects with citizens. Increasingly it appears that government is less in the business of delivering services per se and more in the business of weaving together integrative responses to public problems, where some of the solutions are governmental, some lie in the private sector and others in the non-governmental sector. This is an opportunity to increase government productivity which may not be possible to achieve in any other way. 